\title{
Evaluation of heart fatty acid-binding protein as a rapid indicator for assessment of myocardial damage in pediatric cardiac surgery
}

\author{
Tomomi Hasegawa, MD \\ Naoki Yoshimura, MD \\ Shigeteru Oka, MD \\ Yoshio Ootaki, MD \\ Yoshiya Toyoda, MD \\ Masahiro Yamaguchi, MD
}

From the Department of Cardiothoracic Surgery, Kobe Children's Hospital, Kobe, Japan.

Received for publication Oct 2, 2003; revisions requested Jan 18, 2004; accepted for publication Feb 9, 2004.

Address for reprints: Tomomi Hasegawa, MD, Department of Cardiothoracic Surgery, Kobe Children's Hospital, 1-1-1 Takakura-dai, Suma-ku, Kobe 654-0081, Japan

J Thorac Cardiovasc Surg 2004;127: 1697-702

$0022-5223 / \$ 30.00$

Copyright (C) 2004 by The American Association for Thoracic Surgery

doi:10.1016/j.jtcvs.2004.02.006

Objectives: Perioperative myocardial damage is a major determinant of postoperative cardiac dysfunction for congenital heart disease. Heart fatty acid-binding protein is reported to be a rapid marker of perioperative myocardial damage that peaks earlier than creatine kinase isoenzyme $\mathrm{MB}$ or cardiac troponin $\mathrm{T}$ in adults. The objective of this study was to assess the suitability of using serum concentrations of heart fatty acid-binding protein for evaluation of perioperative myocardial damage in pediatric cardiac surgery.

Methods: After institutional review board approval and informed consent, 100 children undergoing open procedures for congenital heart disease were prospectively enrolled in the study. Mean age at operation was $4.9 \pm 0.4$ years. Serum concentrations of heart fatty acid-binding protein, creatine kinase isoenzyme MB, and cardiac troponin $\mathrm{T}$ were measured serially before operation and at $0,1,2,3$, and 6 hours after aortic declamping. Relationships between serum peak level of heart fatty acid-binding protein and intraoperative and postoperative clinical variables were evaluated.

Results: Serum heart fatty acid-binding protein reached its peak level at 1 hour after declamping in 95 patients $(95 \%)$, which was significantly earlier $(P<.01)$ than serum creatine kinase isoenzyme MB or cardiac troponin T. In addition, serum heart fatty acid-binding protein level immediately after declamping correlated strongly with serum peak heart fatty acid-binding protein level $(r=0.91, P<.01)$. The serum peak level of heart fatty acid-binding protein correlated with those of creatine kinase isoenzyme $\mathrm{MB}(r=0.77, P<.01)$ and cardiac troponin $\mathrm{T}(r=0.80$, $P<.01)$. In the forward stepwise multiple regression analysis, age $(P<.0001)$, aortic crossclamp time $(P<.0001)$, the presence of a ventriculotomy $(P<.001)$, and the lowest hematocrit level during cardiopulmonary bypass $(P<.05)$ were significant intraoperative variables that influenced the release of heart fatty acidbinding protein. There were significant relationships between serum peak heart fatty acid-binding protein level and postoperative inotropic support, duration of intubation, and intensive care unit stay $(P<.01$ for each).

Conclusions: Heart fatty acid-binding protein is a rapid marker for assessment of myocardial damage and clinical outcome in pediatric cardiac surgery. In particular, serum heart fatty acid-binding protein level immediately after aortic declamping may be a potentially useful prognostic indicator of myocardial damage as well as clinical outcome in pediatric cardiac surgery. 


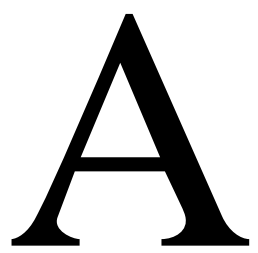

lthough recent advances in surgical technique and myocardial protection have led to significant improvements in pediatric cardiac surgery, little has been reported on assessment of myocardial damage by ischemia and reperfusion in children. ${ }^{1,2}$ In cardiac surgery, intraoperative myocardial damage is a major determinant of postoperative cardiac dysfunction associated with morbidity and mortality. Early and accurate evaluation of myocardial damage would be clinically useful for perioperative management. Currently, heart fatty acidbinding protein (HFABP) has been introduced as a cardiospecific marker for early evaluation of myocardial damage in adult patients undergoing coronary artery bypass grafting. ${ }^{3,4}$ We therefore measured plasma levels of HFABP before and during the postoperative period in patients undergoing open procedures for congenital heart disease with two objectives: to assess the suitability of using serum concentrations of HFABP for evaluation of intraoperative myocardial damage in pediatric cardiac surgery and to clarify whether HFABP can serve as an index to express intraoperative myocardial damage as well as a prognostic indicator for clinical outcome.

\section{Methods}

\section{Patient Population}

Two hundred twenty patients underwent elective open procedures for congenital heart diseases between June 1999 and June 2000. After approval was obtained from the institutional review board and informed consent for all patients was obtained from their parents, we selected 166 patients in this study. To establish a baseline serum HFABP level in patients who underwent surgical procedures, we applied the following exclusion criteria: previous cardiothoracic procedure $(\mathrm{n}=54)$, preoperative inotropic support $(\mathrm{n}=9)$, and postoperative complication resulting in surgical reexploration within 6 hours after an aortic declamping $(n=3)$. Thus, 100 patients undergoing elective open procedures for congenital heart disease between June 1999 and June 2000 were prospectively enrolled in the study protocol. Mean age at operation was $4.9 \pm 0.4$ years, ranging from 3 months to 17 years, and mean body weight was $16.0 \pm 0.9 \mathrm{~kg}$, ranging from 3.5 to $46.2 \mathrm{~kg}$. Diagnoses included ventricular septal defect $(n=56)$, atrial septal defect $(\mathrm{n}=15)$, tetralogy of Fallot $(\mathrm{n}=11)$, valvular disease $(\mathrm{n}=$ $6)$, double-outlet right ventricle $(\mathrm{n}=5)$, complete atrioventricular septal defect $(n=4)$, and others $(n=3)$.

\section{Operative Procedure}

Anesthesia was induced and maintained with fentanyl (50-100 $\mu \mathrm{g} / \mathrm{kg}$ ) and vecuronium. Patients' lungs were ventilated with oxygen, air, and isoflurane, and ventilation was adjusted to maintain normocarbia. Cardiopulmonary bypass (CPB) was instituted with an ascending aortic cannula, bicaval venous cannulas, and a systemic ventricular venting. A systemic flow was maintained between 2.2 and $2.6 \mathrm{~L} /\left(\mathrm{min} \cdot \mathrm{m}^{2}\right)$, and mean arterial pressure was maintained between 40 and $60 \mathrm{~mm} \mathrm{Hg}$. Mild or moderate systemic hypothermia was used. After completion of the surgical repair and
TABLE 1. Composition and characteristics of blood cardioplegia

Sodium ion $(\mathrm{mmol} / \mathrm{L})$

Potassium ion $(\mathrm{mmol} / \mathrm{L})$

Chloride ion $(\mathrm{mmol} / \mathrm{L})$

Magnesium ion $(\mathrm{mmol} / \mathrm{L})$

Calcium ion $(\mathrm{mmol} / \mathrm{L})$

$\mathrm{pH}$

Bicarbonate ion (mmol/L)

Hematocrit (\%)

Osmolarity (m0sm/L)

$97.7 \pm 1.2$

$18.7 \pm 0.3$

$90.4 \pm 0.8$

$1.0 \pm 0.01$

$0.73 \pm 0.01$

$7.51 \pm 0.01$

$17.4 \pm 0.3$

$18.6 \pm 0.6$

$339 \pm 3.1$

All data are shown as mean \pm SEM for each composition.

aortic declamping, rewarming was instituted. CPB was discontinued with minimal inotropic support, and modified ultrafiltration was performed under stable hemodynamic conditions.

\section{Protocol for Myocardial Protection}

Myocardial protection was achieved with intermittent cold blood cardioplegia with topical cardiac cooling in all patients. A dose of $300 \mathrm{~mL} / \mathrm{m}^{2}$ body surface area was initially infused into the aortic root at a pressure of $30 \mathrm{~mm} \mathrm{Hg}$ to achieve cardiac arrest, with subsequent doses of $150 \mathrm{~mL} / \mathrm{m}^{2}$ body surface area infused every 20 minutes. In all patients an additional dose of $300 \mathrm{~mL} / \mathrm{m}^{2}$ body surface area warm $\left(35^{\circ} \mathrm{C}\right)$ blood cardioplegic solution was infused into the aortic root just before the aortic declamping. ${ }^{5}$ Blood cardioplegic solution was made by mixing hyperkalemic crystalloid solution ${ }^{6}$ with oxygenated blood in the ratio of $1: 2$ and then cooled to $9^{\circ} \mathrm{C}$ (Table 1). At the start of reperfusion, the aorta was partially declamped for 3 minutes, and the aortic root pressure was kept at less than $30 \mathrm{~mm} \mathrm{Hg}$ to reduce reperfusion injury. The aorta was then fully declamped. If ventricular fibrillation persisted beyond a few minutes after the aortic declamping, electrical defibrillation was applied to restore normal sinus rhythm.

\section{Blood Samples and Biochemical Analysis}

As markers of myocardial damage, serum concentrations of HFABP, creatine kinase isoenzyme MB (CK-MB), and cardiac troponin $\mathrm{T}(\mathrm{TnT})$ were measured at 6 points during the study protocol as follows: after induction of anesthesia and before skin incision and at $0,1,2,3$, and 6 hours after the aortic declamping. All blood samples were collected through a radial arterial line and centrifuged immediately. The plasma was frozen and stored until biochemical analysis was performed. The serum HFABP level was measured with a sandwich enzyme-linked immunosorbent assay with two distinct murine anti-HFABP monoclonal antibodies (Markit-M H-FABP; Dainippon Pharmaceutical Co Ltd, Osaka, Japan). ${ }^{7}$ Activity of CK-MB was measured with an immunoinhibitory assay, and the serum TnT level was quantified with an enzyme immunoassay (SRL, Tokyo, Japan).

\section{Assessment of Clinical Outcome}

Relationship between serum peak level of HFABP and intraoperative and postoperative clinical variables were evaluated. Intraoperative variables included diagnosis for surgery, durations of CPB and aortic crossclamping, the lowest hematocrit and myocardial temperature during $\mathrm{CPB}$, the presence of a ventriculotomy, and the 
TABLE 2. Intraoperative variables $(\mathbf{n}=\mathbf{1 0 0})$

\begin{tabular}{lc}
\hline Age (mo, mean \pm SEM) & $59 \pm 4(3-209)$ \\
CPB time (min, mean \pm SEM) & $146 \pm 6(47-348)$ \\
Aortic crossclamping time (min, & $77 \pm 4(19-213)$ \\
$\quad$ mean \pm SEM) & $11.6 \pm 0.4$ (3.0-24.0) \\
Myocardial temperature during CPB & \\
$\quad\left({ }^{\circ}\right.$ C, mean \pm SEM) & $17.1 \pm 0.3(11.9-27.9)$ \\
Lowest hematocrit during CPB (\%, & \\
$\quad$ mean \pm SEM) & 21 \\
Ventriculotomy (No.) & 39 \\
Electrical defibrillation (No.) & \\
Diagnosis (No.) & 56 \\
Ventricular septal defect & 15 \\
Atrial septal defect & 11 \\
Tetralogy of Fallot & 6 \\
Valvular disease & 5 \\
Double-outlet right ventricle & 4 \\
Atrioventricular septal defect & 3 \\
Other & \\
\hline
\end{tabular}

requirement of electrical defibrillation for heartbeat recovery after aortic declamping. Postoperative variables included inotrope score and durations of intubation and intensive care unit stay. Inotrope score was defined as follows: the sum of the doses of dopamine $(\mu \mathrm{g} /[\mathrm{kg} \cdot \mathrm{min}])$, dobutamine $(\mu \mathrm{g} /[\mathrm{kg} \cdot \mathrm{min}])$, and epinephrine $(\mu \mathrm{g} /[\mathrm{kg} \cdot \min ] \times 100)$ multiplied by the number of hours that each drug was used. ${ }^{8}$

\section{Statistical Analysis}

All values are expressed as mean \pm SEM. Comparisons of the times taken to reach serum peak levels among the 3 groups (HFABP, CK-MB, and TnT) were performed with the KruskalWallis test. Simple linear regression analysis was performed by the least squares method to determine the relationship of serum levels in the 3 groups. The relationship between intraoperative variables and serum peak levels in the 3 groups was analyzed with the forward stepwise regression. Spearman rank correlation coefficients (2-tailed) were used to evaluate whether serum peak HFABP level was correlated with postoperative clinical variables. All statistical analyses were performed with the Statview (version 5.0) software package (SAS Institute, Inc, Cary, NC).

\section{Results}

\section{Clinical Outcome}

The intraoperative data are shown in Table 2. There were no in-hospital deaths or major postoperative complications. Transient electrocardiographic changes of minor ST-segment change were observed in 17 patients but were unrelated to the elevation of serum levels of biochemical markers. Inotropic support was required with dopamine (range $3-12 \mu \mathrm{g} /[\mathrm{kg} \cdot \mathrm{min}]$ ) in all cases, with dobutamine (range $2.5-10 \mu \mathrm{g} /[\mathrm{kg} \cdot \mathrm{min}])$ in 38 cases, and with epinephrine (range $0.025-0.15 \mu \mathrm{g} /[\mathrm{kg} \cdot \mathrm{min}]$ ) in 9 cases. Inotrope score was $561 \pm 89$ (range 51-6648). Durations of intubation and intensive care unit stay were $33 \pm 4.5$ hours (range 3-283 hours) and $4.5 \pm 0.5$ days (range 1-41 days), respectively.

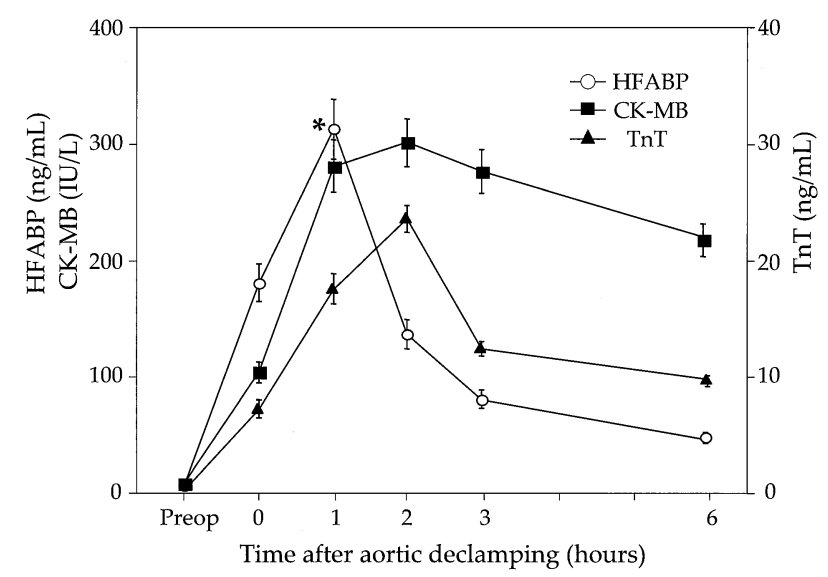

Figure 1. Serum levels of HFABP (open circles), CK-MB (filled squares), and TnT (filled triangles) during study protocol. Results are expressed as mean \pm SEM (error bars). Asterisk indicates $P$ $<.01$; time to reach serum peak level was significantly earlier for HFABP than for CK-MB and TnT.

\section{Serial Changes in Biochemical Markers}

Serial changes in HFABP, CK-MB, and TnT levels are illustrated in Figure 1. The baseline serum HFABP level before the operation ranged from 1.1 to $8.6 \mathrm{ng} / \mathrm{mL}$ (mean $4.3 \pm 0.2 \mathrm{ng} / \mathrm{mL}$ ). Serum HFABP level rose sharply from the baseline to the peak and reached the peak at 1 hour after aortic declamping, then quickly normalized without double peak formation. Serum peak HFABP level ranged from 48 to $1200 \mathrm{ng} / \mathrm{mL}$ (mean, $316 \pm 26 \mathrm{ng} / \mathrm{mL}$ ). The baseline serum CK-MB level before the operation ranged from 2.3 to 18.0 IU/L (mean $6.8 \pm 0.3 \mathrm{IU} / \mathrm{L}$ ). Serum TnT before the operation was not detectable in all patients. Serum CK-MB reached the peak level at 2 hours after declamping and gradually declined with a persistently high level. Serum peak CK-MB level ranged from 78 to 1537 IU/L (mean 337 $\pm 24 \mathrm{IU} / \mathrm{L})$. Serum TnT level also peaked at 2 hours after declamping, ranging from 5 to $55 \mathrm{ng} / \mathrm{mL}$ (mean $27 \pm 1.3$ $\mathrm{ng} / \mathrm{mL})$. Serum HFABP reached the peak level at 1 hour in 95 patients $(95 \%)$ and within 2 hours after declamping in all patients. In contrast, peak levels of serum CK-MB and TnT were seen at a range of 1 to 6 hours after declamping. The time taken to reach serum peak level was significantly less for HFABP than for the other 2 groups $(P<.01$ by Kruskal-Wallis test).

\section{Correlations Between Serum Peak Levels of Biochemical Markers}

Serum peak HFABP level correlated significantly with serum peak CK-MB level $(r=0.766, P<.01$; Figure $2, A)$ and serum peak TnT level $(r=0.796, P<.01$; Figure $2, B$ ). Serum HFABP level immediately after aortic declamping correlated strongly with serum peak HFABP level $(r=$ $0.910, P<.01$; Figure 3). 

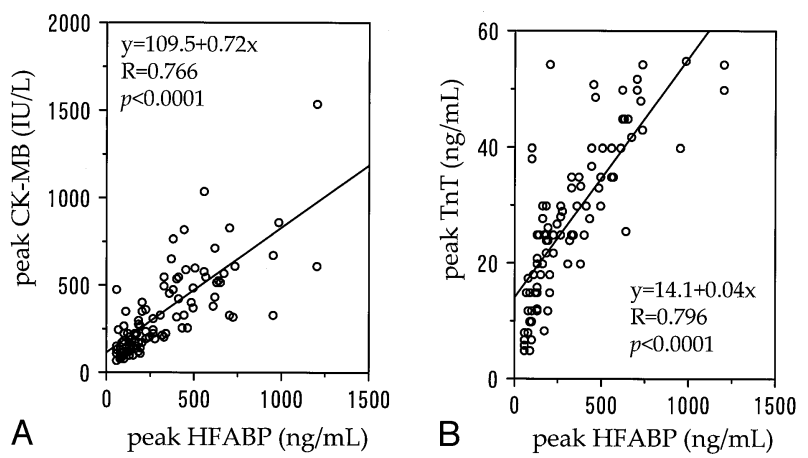

Figure 2. Correlations between serum peak HFABP level and serum peak CK-MB (A) and TnT (B) levels.

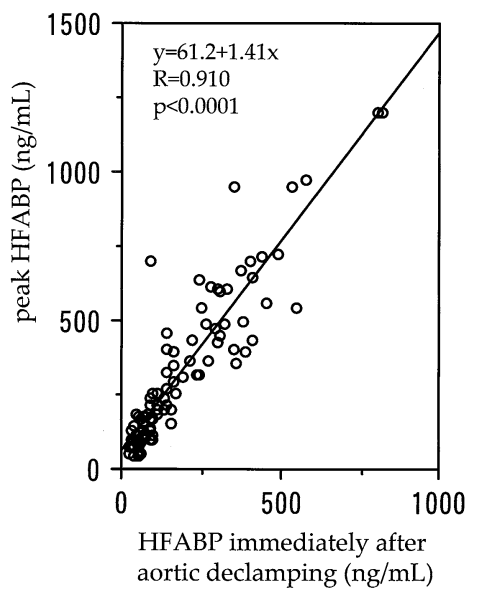

Figure 3. Correlation between serum HFABP level immediately after aortic declamping and serum peak HFABP level.

\section{Intraoperative Variables for the Release of HFABP}

In the forward stepwise multiple regression analysis, age ( $P$ $<.0001)$, aortic crossclamping time $(P<.0001)$, the presence of a ventriculotomy $(P<.001)$, and the lowest hematocrit during CPB $(P<.05)$ were significant intraoperative variables that influenced the release of HFABP (Table 3A). Age, aortic crossclamping time, and the presence of a ventriculotomy were also significantly correlated with the release of CK-MB and TnT $(P<.01$ for each; Tables 3B and $3 \mathrm{C})$.

\section{Relationship of HFABP Level to Postoperative Outcome Variables}

Serum peak HFABP level correlated significantly with inotrope score, intubation time, and intensive care unit stay, with Spearman rank correlation coefficients greater than $0.50(P<.01$ for each; Table 4$)$. In particular, a good correlation between serum peak HFABP level and inotrope score was observed, with a correlation coefficient of 0.73 (Figure 4).
TABLE 3A. Forward stepwise regression analysis for peak $\operatorname{HFABP}(\mathrm{ng} / \mathrm{mL})$

\begin{tabular}{lrrrrr}
\hline Variable & Coefficient & SE & $\boldsymbol{t}$ Value & $\boldsymbol{P}$ value \\
\hline Constant & -41.47 & 116.62 & & \\
Age (mo) & -2.49 & 0.41 & -6.07 & $<.0001$ \\
Aortic crossclamping time (min) & 2.92 & 0.51 & 5.76 & $<.0001$ \\
Ventriculotomy (yes = 1, no $=0)$ & 167.15 & 47.43 & 3.52 & .0007 \\
Lowest hematocrit level (\%) & 14.18 & 6.55 & 2.16 & .0330
\end{tabular}

Adjusted $R^{2}=0.54$, analysis of variance for the full regression $P<.001$.

TABLE 3B. Forward stepwise regression analysis for peak CK-MB (IU/L)

\begin{tabular}{lrrrr}
\hline Variable & Coefficient & SE & $\boldsymbol{t}$ Value & $\boldsymbol{P}$ value \\
\hline Constant & 422.09 & 71.57 & & \\
Age (mo) & -1.60 & 0.38 & -4.17 & $<.0001$ \\
Aortic crossclamping time $(\mathrm{min})$ & 1.45 & 0.49 & 2.93 & .0042 \\
Ventriculotomy (yes $=1$, no $=0)$ & 266.94 & 44.45 & 6.01 & $<.0001$ \\
Myocardial temperature $\left({ }^{\circ} \mathrm{C}\right)$ & -13.73 & 4.20 & -3.27 & .0015 \\
\hline
\end{tabular}

Adjusted $R^{2}=0.53$, analysis of variance for the full regression $P<.001$.

TABLE 3C. Forward stepwise regression analysis for peak $\mathrm{TnT}(\mathrm{ng} / \mathrm{mL})$

\begin{tabular}{lrrrr}
\hline Variable & Coefficient & SE & $\boldsymbol{t}$ Value & $\boldsymbol{P}$ value \\
\hline Constant & 21.96 & 2.84 & & \\
Age (mo) & -0.11 & 0.02 & -4.52 & $<.0001$ \\
Aortic crossclamping time (min) & 0.12 & 0.03 & 4.12 & $<.0001$ \\
Ventriculotomy (yes $=1$, no $=0$ ) & 8.61 & 2.79 & 3.08 & .0027
\end{tabular}

Adjusted $R^{2}=0.40$, analysis of variance for the full regression $P<.001$.

TABLE 4. Correlation between serum peak HFABP levels and postoperative clinical variables

\begin{tabular}{lrccc}
\hline Variable & \multicolumn{3}{c}{ Interduatile } & \\
\hline Inotrope score* & 228 & $152-522$ & 0.799 & $<.01$ \\
Intubation time (h) & 16 & $8-26$ & 0.598 & $<.01$ \\
Intensive care unit stay (d) & 2 & $2-6$ & 0.600 & $<.01$
\end{tabular}

*Sum of doses of dopamine $(\mu \mathrm{g} /[\mathrm{kg} \cdot \mathrm{min}])$, dobutamine $(\mu \mathrm{g} /[\mathrm{kg} \cdot \mathrm{min}])$, and epinephrine $(\mu \mathrm{g} /[\mathrm{kg} \cdot \mathrm{min}] \times 100)$ multiplied by number of hours each drug was used.

\section{Discussion}

Important characteristics to determine the utility of a biochemical marker for myocardial damage are its cellular localization, aqueous solubility, clearance from blood circulation, specificity for myocardium, and detectability in plasma. ${ }^{9}$ Recently, HFABP has been introduced as a plasma marker for early evaluation of myocardial damage ${ }^{3,4}$ and estimation of infarct size ${ }^{10}$ in adult patients. HFABP is a soluble cytoplasmic protein consisting of 132 amino acid 
residues and weighing $14.9 \mathrm{kd}$, and it is abundant especially in the cytoplasm of cardiomyocyte in free form. HFABP is immunologically distinguishable from other types of fatty acid-binding protein: liver, intestine, adipocyte, myelin, brain, and so on. Its physiologic role is the transport of long-chain fatty acids from the cell membrane to their intracellular sites of metabolism in the mitochondria, where they enter the citric acid cycle. Because this protein features a low-molecular weight and a cytosolic localization, it leaks out easily from the injured myocardium and immediately enters the blood circulation. ${ }^{11-13}$

In our study the preoperative baseline serum HFABP level in children was congruent with that reported previously for adults (mean $3.8 \pm 0.2 \mathrm{ng} / \mathrm{mL}$, range 1.9-5.5 $\mathrm{ng} / \mathrm{mL}$ ). ${ }^{3}$ Judging from this result, we can say with fair certainty that normal preoperative HFABP values in children are in the same range as those in adults. On the other hand, the serum peak HFABP level showed a greater tendency to increase in children than adults. The serum peak HFABP level in children without a ventriculotomy was 48 to $1200 \mathrm{ng} / \mathrm{mL}$ (mean $260 \pm 25.7 \mathrm{ng} / \mathrm{mL}$ ) in our series, but Suzuki and colleagues ${ }^{3}$ have reported that the level in adults ranges from 64.9 to $139.0 \mathrm{ng} / \mathrm{mL}$ (mean $93.2 \pm 5.4 \mathrm{ng} / \mathrm{mL}$ ). Previously, Toyoda and associates ${ }^{5}$ implied that serum HFABP reached to peak level at 1 hour after declamping in pediatric cardiac surgery. In this study, serum HFABP level formed a sharp peak at 1 hour after aortic declamping, and $95 \%$ of the patients reached their individual peak levels at this time point. Suzuki and colleagues ${ }^{3}$ demonstrated that HFABP peaked $47.3 \pm 2$ minutes after the release of the aortic crossclamp in a group of 20 patients with coronary heart disease. Fransen and colleagues ${ }^{14}$ showed that perioperative myocardial damage could already be diagnosed from the release of HFABP into plasma at 0.5 hours after reperfusion in 57 patients with various cardiac diagnoses and operations. Serum HFABP reached the peak level significantly earlier than did CK-MB and TnT. After reaching peak level, serum HFABP decreased quickly in all patients, whereas serum CK-MB and TnT levels remained at high levels or showed double peaks in $12 \%$ or $14 \%$ of the patients, respectively. These results suggest that HFABP is expected to be a sensitive and specific marker for use in early detection of myocardial damage. Serum peak HFABP level also revealed a significant correlation with serum HFABP level immediately after declamping. We believe that serum HFABP level immediately after declamping can predict serum peak HFABP level and rapidly detect myocardial damage. Although it currently takes approximately 1 hour to measure serum HFABP level with the sandwich enzyme immunoassay kit, we can get information about myocardial damage earlier with HFABP than with CK-MB or TnT.

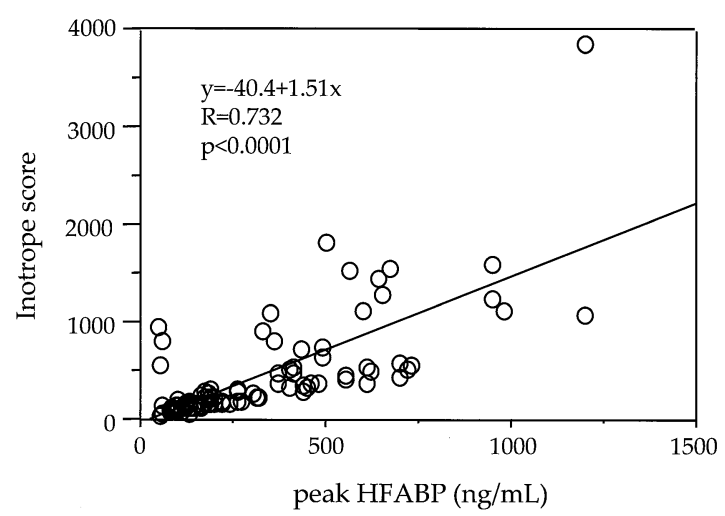

Figure 4. Correlation between serum peak HFABP level and inotrope score (sum of doses of dopamine $[\mu \mathrm{g} /(\mathrm{kg} \cdot \mathrm{min})]$, dobutamine $[\mu \mathrm{g} /(\mathrm{kg} \cdot \mathrm{min})]$, and epinephrine $[\mu \mathrm{g} /(\mathrm{kg} \cdot \mathrm{min}) \times 100]$ multiplied by number of hours each drug was used).

We found that myocardial damage with the release of HFABP as well as CK-MB and TnT was dependent on age, aortic crossclamping time, and the presence of ventriculotomy in the stepwise multiple regression model. Taggart and associates ${ }^{1}$ have reported that age and ischemic time are highly significant explanatory variables for the release of CK-MB and TnT and that the presence of an atriotomy or ventriculotomy is a significant explanatory variable for the release of TnT. A negative correlation was found between age and the release of HFABP. It seems that the younger patients are, the more vulnerable their myocardia are to injury during cardiac surgery. Trauma to the pediatric heart during surgery, not only from direct surgical incisions such as ventriculotomy but also from technical procedures such as aortic crossclamping, causes myocardial cell damage and the release of biochemical markers. In our study $69 \%$ of the patients did not require any blood products during and after surgery. On the other hand, our results showed that lowest hematocrit during $\mathrm{CPB}$ correlated significantly with serum peak level of HFABP. CPB with hemodilution is reported to be associated with organ dysfunction as a result of tissue edema and hypoxemia. ${ }^{15}$ Leung and associates ${ }^{16}$ have speculated that acute and severe isovolemic hemodilution produces an imbalance in myocardial oxygen supply and demand, resulting in myocardial ischemia. We should take great care to avoid excessive hemodilution in pediatric cardiac surgery without blood transfusion.

This study suggests that the serum HFABP level after aortic declamping may be a prognostic indicator for postoperative clinical outcome. Higher elevations of serum HFABP level required a larger amount of inotropic support and a longer intubation time, with resultant prolongation of intensive care unit stay. When we study these relationships in larger numbers, it may be possible to determine a thresh- 
old level of serum HFABP as a risk factor in the postoperative clinical course.

This study population was carefully selected to establish a baseline serum HFABP level in pediatric patients undergoing cardiac surgery. Because of this selectivity, the limitation of this study is that no neonatal patients and few cyanotic patients were included in our series. Another possible limitation is that postoperative clinical variables can differ according to the subjective judgment of the clinician managing the patient. Clinician bias is, however, unlikely to have been a confounding factor because the postoperative management was strictly in accordance with our unit protocol, and the results were not available to the clinician.

In conclusion, serum HFABP reached the peak level significantly earlier than serum CK-MB or TnT, and the peak level of HFABP could be predicted from the level immediately after aortic declamping. Our data indicate that HFABP is a rapid indicator for the assessment of myocardial damage and clinical outcome in pediatric cardiac surgery. Prognostic information of HFABP makes it possible for us to check on the quality of surgical technique and myocardial protection and to start early treatment for myocardial damage.

\section{References}

1. Taggart DP, Hadjinikolas L, Wong K, Yap J, Hooper J, Kemp M, et al. Vulnerability of paediatric myocardium to cardiac surgery. Heart. 1996;76:214-7.

2. Lipshultz SE, Rifai N, Sallan SE, Lipsitz SR, Dalton V, Sacks DB, et al. Predictive value of cardiac troponin $\mathrm{T}$ in pediatric patients at risk for myocardial injury. Circulation. 1997;96:2641-8.

3. Suzuki K, Sawa Y, Kadoba K, Takahashi T, Ichikawa H, Kagisaki K, et al. Early detection of cardiac damage with heart fatty acid-binding protein after cardiac operations. Ann Thorac Surg. 1998;65:54-8.

4. Petzold T, Feindt P, Sunderdiek U, Boeken U, Fischer Y, Gams E. Heart-type fatty acid binding protein (hFABP) in the diagnosis of myocardial damage in coronary artery bypass grafting. Eur J Cardiothorac Surg. 2001;19:859-64.
5. Toyoda Y, Yamaguchi M, Yoshimura N, Oka S, Okita Y. Cardioprotective effects and the mechanisms of terminal warm blood cardioplegia in pediatric cardiac surgery. J Thorac Cardiovasc Surg. 2003;125: $1242-51$

6. Roe BB, Hutchinson JC, Ullyot DJ, Smith DL. Myocardial protection with cold, ischemic, potassium-induced cardioplegia. J Thorac Cardiovasc Surg. 1977;73:366-70.

7. Ohkaru Y, Asayama K, Ishii H, Nishimura S, Sunahara N, Tanaka T, et al. Development of a sandwich enzyme-linked immunosorbent assay for the determination of human heart type fatty acid-binding protein in plasma and urine by using two different monoclonal antibodies specific for human heart fatty acid-binding protein. J Immunol Methods. 1995;178:99-111.

8. Kulik TJ, Moler FW, Palmisano JM, Custer JR, Mosca RS, Bove EL, et al. Outcome-associated factors in pediatric patients treated with extracorporeal membrane oxygenator after cardiac surgery. Circulation. 1996;94(9 Suppl):II63-8.

9. Adams JE, Abendschein DR, Jaffe AS. Biochemical markers of myocardial injury: is MB creatine kinase the choice for the 1990s? Circulation. 1993;88:750-63.

10. Glats JF, Kleine AH, Van Nieuwenhoven FA, Hermens WT, Van Dieijen-Visser MP, Van der Vusse GJ. Fatty acid-binding protein as a plasma marker for the estimation for myocardial infarct size in humans. Br Heart J. 1994;71:135-40.

11. Schaap FG, van der Vusse GJ, Glatz JF. Fatty acid-binding proteins in the heart. Mol Cell Biochem. 1998;180:43-51.

12. Okamoto F, Sohmiya K, Ohkaru Y, Kawamura K, Asayama K, Kimura $\mathrm{H}$, et al. Human heart-type cytoplasmic fatty acid-binding protein (H-FABP) for the diagnosis of acute myocardial infarction. Clinical evaluation of H-FABP in comparison with myoglobin and creatine kinase isoenzyme MB. Clin Chem Lab Med. 2000;38:231-8.

13. Watanabe T, Ohkubo Y, Matsuoka H, Kimura H, Sakai Y, Ohkaru Y, et al. Development of a simple whole blood panel test for detection of human heart-type fatty acid-binding protein. Clin Biochem. 2001;34: 257-63.

14. Fransen EJ, Maessen JG, Hermens WT, Glantz JF. Demonstration of ischemia-reperfusion injury separate from postoperative infarction in coronary artery bypass graft patients. Ann Thorac Surg. 1998;65:4853.

15. Davies MJ, Nguyen K, Gaynor JW, Elliott MJ. Modified ultrafiltration improves left ventricular systolic function in infants after cardiopulmonary bypass. J Thorac Cardiovasc Surg. 1998;115:361-70.

16. Leung JM, Weiskopf RB, Feiner J, Hopf HW, Kelley S, Viele M, et al. Electrocardiographic ST-segment changes during acute, severe isovolemic hemodilution in humans. Anesthesiology. 2000;93:1004-10. 